\title{
Profile of belatacept and its potential role in prevention of graft rejection following renal transplantation
}

This article was published in the following Dove Press journal:

Drug Design, Development and Therapy

30 November 2010

Number of times this article has been viewed

\author{
Gaurav Gupta \\ Karl L Womer \\ Division of Nephrology, Department \\ of Medicine, Johns Hopkins University \\ School of Medicine, Baltimore, \\ MD, USA
}

\begin{abstract}
The last several decades have witnessed a substantial decrease in the incidence of acute allograft rejection following kidney transplantation, although commensurate improvements in long-term graft function have not been realized. As a result, the primary focus of new immunosuppressive drug development has expanded to include ease of use and improved side effect profile, including reduced nephrotoxicity, in addition to the more traditional goal of improved short-term outcomes. A number of novel drugs are currently under investigation in Phase I, II, or III clinical trials, primarily to replace the nephrotoxic but highly effective calcineurin inhibitors. Belatacept is a humanized antibody that inhibits $\mathrm{T}$ cell costimulation and has shown encouraging results in multiple Phase II and III trials. This article reviews the mechanism of action of belatacept, as well as published and preliminary results of the Phase I-III clinical trials involving this novel immunosuppressive agent.
\end{abstract}

Keywords: kidney transplantation, T cell costimulation, immunosuppression, graft rejection, post-transplant lymphoproliferative disease

\section{Introduction}

Kidney transplantation is the treatment of choice for end-stage renal disease. ${ }^{1}$ A total of 292,427 kidney transplants were performed in the US by the end of $2009 .^{2}$ The use of better donor-recipient selection algorithms, novel surgical techniques, and improved post-transplant care have all led to a significant improvement in short-term graft survival, which currently approaches $90 \%$ in the first year after transplant. ${ }^{3}$ However, the most significant impact in this improvement is the introduction of more potent immunosuppressive therapy. The goal of immunosuppressive therapy in renal transplantation is to minimize acute and chronic rejection while, at the same time, balancing these beneficial effects with their adverse effects, which include the development of increased cardiovascular risk factors, infections, and malignancies. Current immunosuppression strategies are primarily based on an induction regimen using a monoclonal or polyclonal antibody, followed by "maintenance immunosuppression" consisting of calcineurin inhibitors (cyclosporine or tacrolimus), an antiproliferative agent (mycophenolate mofetil), and low-dose corticosteroids (prednisone). ${ }^{4}$

Unfortunately, improvement in short-term graft survival has not been reflected in improved long-term outcomes. ${ }^{5}$ Five-year graft survival continues to lag behind and is currently estimated to be approximately $72 \% .^{6}$ The primary causes of late allograft loss include chronic allograft dysfunction and death with a functioning graft. $^{7}$ Chronic allograft dysfunction can result from multiple causes, including chronic immune-mediated injury, interstitial fibrosis, and tubular atrophy, as well as
Correspondence: Karl L Womer Ross 947, 720 Rutland Avenue, Baltimore, MD 21205, USA

Tel + I 4105023707

Fax +l 4105025944

Email kwomerl@jhmi.edu 
the chronic toxic effect of calcineurin inhibitors. ${ }^{8}$ Histologic data from protocol renal allograft biopsies demonstrated the presence of calcineurin inhibitor-induced nephrotoxicity in $50 \%$ of renal transplant recipients at two years and $100 \%$ at 10 years after transplant. ${ }^{8}$ Long-term mortality in the adult renal transplant recipient is also estimated to be nearly four times that of the general population. ${ }^{9}$ A large proportion of this decreased patient survival is secondary to an increased burden of cardiovascular disease and infections in renal transplant recipients. ${ }^{10}$ Calcineurin inhibitors have been associated with the development and worsening of hypertension and hyperlipidemia, as well as diabetes. ${ }^{11}$

Various calcineurin inhibitor minimization and withdrawal strategies have been attempted, with mixed results. ${ }^{12,13}$ The use of mTOR (mammalian target of rapamycin) inhibitors (sirolimus and everolimus) for calcineurin inhibitor minimization/withdrawal has been hampered by an adverse side effect profile. ${ }^{14}$ Therefore, calcineurin inhibitors currently remain the cornerstone of maintenance immunosuppression in renal transplant recipients. By the end of 2007, close to $99 \%$ of renal transplant recipients were discharged on calcineurin inhibitors. ${ }^{15}$ The current trend in drug development is focused on preservation of long-term function and minimization of the adverse reactions of immunosuppressive drugs. Multiple small molecules and biologic agents are currently being studied. ${ }^{16,17} \mathrm{~T}$ cell costimulation blockade is a promising approach and is being intensively investigated since the development of belatacept. In this review we discuss the mechanism of action, preclinical and clinical data, and the side effect profile of belatacept.

\section{Mechanism of alloimmune recognition}

The ability of $\mathrm{T}$ cells to recognize nonself antigens is critical for an effective immune response. ${ }^{18}$ Antigen-presenting cells (dendritic cells, macrophages, and B cells) are specialized cells capable of activating $\mathrm{T}$ cells. To trigger an adequate alloimmune response, a series of pathways must be activated. All immunosuppressive agents in use today interfere with specific steps of these pathways. First, nonself or alloantigens are displayed by major histocompatibility complex (MHC) molecules on the surface of antigen-presenting cells (see Figure 1). "Signal 1" is transmitted when the MHC - allopeptide complex engages a specific $T$ cell receptor, leading to initiation of the signaling process from the CD3 complex. This interaction leads to activation of several signal transduction pathways, including the calcium - calcineurin pathway, which activates the nuclear factor of activated $\mathrm{T}$ cell.

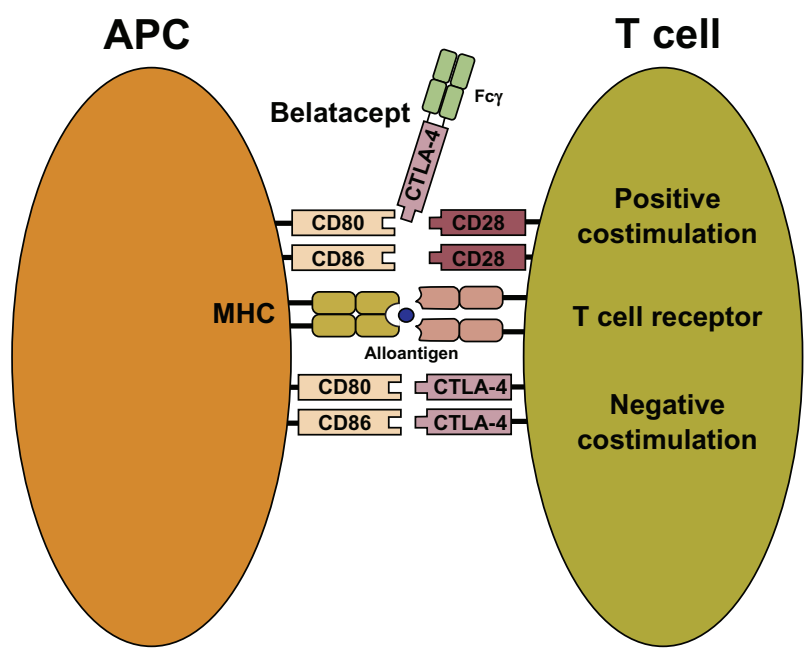

Figure I T cell costimulation and mechanism of action for belatacept. "Signal I" is delivered through the $\mathrm{T}$ cell receptor after presentation of alloantigen bound to MHC molecules on APCs. "Signal 2" or costimulation is initiated through the binding of CD80 and CD86 on APCs to CD28 and its homolog, CTLA4, on T cells. Belatacept, developed through fusion of CTLA4 with the Fc constant region of human immunoglobulin ( $\mathrm{Fc} \gamma$ ), blocks APC stimulation of T cell CD28, thereby inhibiting the immune response.

Abbreviations: APC, antigen-presenting cells; CTLA4, cytotoxic T lymphocyteassociated antigen 4; MHC, major histocompatibility complex.

To amplify the T cell response further, "Signal 2" or "costimulation" must be transmitted (see Figure 1). This signal is mediated by the interaction of CD80 (B7.1) and CD86 (B7.2) on antigen-presenting cells with specific $\mathrm{T}$ cell receptors (CD28 and its homolog, cytotoxic T lymphocyte-associated antigen 4 [CTLA4]). CD28, a disulfide-linked homodimeric transmembrane member of the immunoglobulin superfamily, is constitutively expressed on all naïve CD4 and CD8 T cells, although some mature T cells, especially memory CD8 T cells, are CD28-negative. ${ }^{19}$ In contrast with CD28, CTLA4 delivers signals that attenuate $\mathrm{T}$ cell proliferation. Ligation of CD28 by CD80/86 is required for clonal expansion of naïve CD4 T cells. Once activated, T cells express increased concentration of CTLA4. Because CTLA4 has a higher affinity than CD28 for the CD80/86 ligand, it binds to most of the available molecules, effectively shutting down further $\mathrm{T}$ cell proliferation. Thus, costimulatory molecules can provide positive or negative signals to $\mathrm{T}$ cells. For complete $\mathrm{T}$ cell activation and differentiation, costimulation is essential. In the absence of a "signal", T cells will either undergo apoptosis or develop donor-specific anergy. ${ }^{20}$ Activation of Signals 1 and 2 leads to expression of cytokines, especially interleukin-2. These cytokines activate the mTOR via the janus kinase 3 and phosphoinositide-3 kinase signal transduction pathways, leading to further propagation of the lymphocyte cell cycle. This last step is termed "Signal 3". 


\section{Mechanism of action}

Molecules that prevent $\mathrm{T}$ cell costimulation have emerged as promising immunomodulatory agents. CTLA4-Ig (abatacept) was the first molecule to be developed by fusion of the extracellular domain of CTLA4 with the constant region fragment (Fc $\gamma$ ) of human IgG1 to increase its serum half-life. ${ }^{21}$ Given the higher affinity of CTLA4 for CD80/86, CTLA4-Ig should theoretically block antigen-presenting cell stimulation of $\mathrm{T}$ cells through $\mathrm{CD} 28$, thereby terminating the immune response (see Figure 1). However, the Fc $\gamma$ region can independently bind to multiple receptors that modulate immune responses, including antibody-dependent cellular cytotoxicity and complement-dependent cytotoxicity. Thus, in abatacept, a series of directed cysteine to serine mutations were introduced in the hinge region to reduce this Fc-mediated binding. ${ }^{21}$ Although abatacept proved to be highly efficacious for autoimmune $\mathrm{T}$ cell-mediated autoimmune disorders, such as rheumatoid arthritis and psoriasis, it was found to be an inadequate maintenance immunosuppressive agent in nonhuman primate models of transplantation. ${ }^{22-24}$ Studies into potential reasons for this disconnect found that although CTLA4 binds with a much higher avidity to CD80 and CD86 than does CD28, CTLA4-Ig was significantly less potent at inhibiting CD86-dependent as opposed to CD80-dependent costimulation. ${ }^{25}$

Thus, it was reasoned that a CTLA4-Ig protein with a higher avidity for $\mathrm{CD} 86$ could be developed. Using a rational mutagenesis and screening strategy, a daughter molecule, LEA29Y (belatacept, Bristol-Myers Squibb, New York, NY, USA), with two amino acid substitutions (L104->E and A29->Y), was developed. ${ }^{26}$ Belatacept was found to bind four times more avidly to CD86 and two times more avidly to CD80 than the parent compound, abatacept. This improved binding results in an approximately 10 -fold more potent inhibition of T cell activation. ${ }^{26}$ Flow cytometric studies in renal transplant patients have demonstrated that belatacept saturates both CD80 and CD86 receptors in whole blood and dendritic cell cultures, although the belatacept concentrations required for CD86 receptor saturation were approximately 10 -fold higher than those required for CD80 saturation. ${ }^{27}$ In a study published only in abstract form, Davis et al reported that, like abatacept, belatacept did not mediate antibody-dependent cellular cytotoxicity or complement-dependent cytotoxicity of target B cells through its Fe domain. These findings suggest that the immunomodulatory activity is mediated predominantly through inhibition of CD28 signaling. ${ }^{28}$

In humans, CD4+ CD25+ regulatory T cells (Tregs) constitute $5 \%-15 \%$ of peripheral CD4+ $\mathrm{T}$ cells, and are surmised to have an important suppressive role in the pathologic immune responses after transplantation..$^{29}$ The fork head transcription factor, FOXP3, is essential for the development of Tregs. Interleukin- 2 and CD 28 costimulation has been shown to be an essential survival factor for Tregs. ${ }^{30}$ Thus, drugs that target these pathways could have a potentially deleterious effect on Treg survival. ${ }^{31}$ Reassuringly, data from a Phase II belatacept renal transplant study showed that costimulation blockade did not interfere with Treg homeostasis. The authors presented several hypotheses as to why Treg homeostasis was not altered by belatacept, including the possibility that human Tregs might not be as sensitive to CD28 costimulation blockade as mouse Tregs; that allotransplantation could result in the development of CD28-independent adaptive Tregs; that other costimulatory molecules, like CD2, could function as a substitute for the CD28 pathway; and, finally, that long-term intermittent dosing of belatacept could have a subsaturating effect on CD86, allowing Tregs to receive sufficient CD28 signaling in order to maintain their survival. A significant increase in intragraft FOXP3 $+\mathrm{T}$ cells was also noted in belatacept-treated patients. The authors surmised that this may lead to better resolution of graft rejection episodes and potentially promote tolerance. ${ }^{32}$ The number of patients was too small, however, to evaluate the impact of this finding on overall graft survival.

\section{Maintenance immunosuppressant in renal transplantation Preclinical trials}

Various in vitro and in vivo studies have examined the efficacy of combined CD80/86 blockade. Vierboom et al showed that a combination of anti-CD80 and anti-CD86 monoclonal antibodies resulted in a complete abrogation of the primary alloimmune response among peripheral mononuclear blood cells obtained from Rhesus monkeys..$^{33}$ In an animal model, Kirk et al demonstrated that administration of anti-CD80 and anti-CD86 monoclonal antibodies resulted in a delayed onset of acute allograft rejection without global $\mathrm{T}$ cell or B cell depletion. However, although treatment with monoclonal antibodies alone (without other immunosuppressive drugs) was sufficient to maintain graft survival, rejection occurred as soon as the treatment ceased, suggesting that the therapy was not tolerogenic. ${ }^{34}$ Montgomery et al showed a greater rejection-free survival rate but a lack of durable tolerance with combination anti-CD80, anti-CD86, and anti-CD154 monoclonal antibodies. ${ }^{35}$ In a study on human and pig peripheral mononuclear blood cells, Emamaullee et al showed that both belatacept and basiliximab, either as 
monotherapy or as combination therapy, potently inhibited allogeneic immune responses. ${ }^{36}$

Table 1 lists the results of various animal studies examining the use of belatacept in solid organ transplantation. In a nonhuman primate model, Larsen et al's landmark study demonstrated that belatacept monotherapy was inferior to combination therapy with belatacept and conventional immunosuppressive drugs in preventing allograft rejection. ${ }^{26}$ Importantly, belatacept did prevent development of donorspecific antibodies, which is a major contributor to chronic allograft loss in clinical settings. ${ }^{37}$

\section{Clinical trials}

Table 2 lists the ongoing and completed clinical trials investigating the use of belatacept in renal transplantation. The first clinical trial on the use of belatacept in renal transplantation was a Phase II noninferiority trial comparing the efficacy of belatacept with cyclosporine for prevention of acute rejection at six months post-transplant. ${ }^{38}$ In a partially blinded, parallel group, multicenter study, the Belatacept Study Group randomized 218 renal transplant recipients to receive a more intensive (11 infusions of $10 \mathrm{mg} / \mathrm{kg}$ over the first six months, followed by $5 \mathrm{mg} / \mathrm{kg}$ every 4-8 weeks) or less intensive (five infusions of $10 \mathrm{mg} / \mathrm{kg}$ over the first three months, followed by $5 \mathrm{mg} / \mathrm{kg}$ every 4-8 weeks) belatacept regimen or cyclosporine. Belatacept was administered as a 30-minute intravenous infusion. All patients also received mycophenolate mofetil and corticosteroids as maintenance immunosuppression and induction with basiliximab. At six months, the incidence of acute rejection was similar in all three groups, being $7 \%, 6 \%$, and $8 \%$ in the more intensive belatacept, less intensive belatacept, and cyclosporine groups, respectively. The grades of acute rejection were also similar, although the less intensive belatacept group experienced a higher incidence of subclinical rejection and treated episodes of subclinical rejection (20\% and 15\%) compared with the more intensive belatacept (9\% and $8 \%$ ) and cyclosporine (11\% and 7\%) groups. Most importantly, glomerular filtration rate, as measured by iohexol clearance, was significantly higher in the belatacept groups compared with the cyclosporine arm. Consistent with this finding, protocol biopsies demonstrated a $15 \%-24 \%$ reduction in the incidence of chronic allograft nephropathy in the belatacept groups. The belatacept groups had a statistically significant lower risk of developing diabetes and need for treatment of hyperlipidemia, and a lower incidence of hypertension.

In a recently presented Phase II study, 89 Epstein-Barr virus (EBV) seropositive adult renal transplant recipients were randomized 1:1:1 to receive belatacept + mycophenolate mofetil $(n=33)$, belatacept + sirolimus $(n=26)$, or tacrolimus + mycophenolate mofetil $(\mathrm{n}=30)$. All patients received thymoglobulin induction. Although the overall glomerular filtration rate was better in the belatacept-treated groups, acute rejection rates were higher in the belatacept + mycophenolate mofetil arm. At the end of 12 months, 2/33 patients in the belatacept + mycophenolate mofetil group and $2 / 26$ patients in the belatacept + sirolimus group had lost their allograft compared with none in the tacrolimus + mycophenolate mofetil group. The authors concluded that use of belatacept in renal transplant recipients may enable calcineurin inhibitor and corticosteroid avoidance, with acceptable rates of acute rejection and improved glomerular filtration rate, although graft loss remains a concern. ${ }^{39}$

BENEFIT (Belatacept Evaluation of Nephroprotection and Efficacy as First line Immunosuppression Trial) is a three-year, Phase III clinical trial that randomized patients to three groups, ie, cyclosporine $(n=231)$, less intensive belatacept $(n=231)$, and more intensive belatacept $(n=225)$. Patients received induction with basiliximab and were maintained on mycophenolate mofetil and corticosteroids. Based

Table I Animal studies of belatacept in solid organ transplantation

\begin{tabular}{|c|c|c|c|}
\hline Animal model & Transplant organ & Drug combination & Median survival \\
\hline \multirow[t]{5}{*}{ Rhesus monkey ${ }^{26}$} & Renal allograft & Abatacept monotherapy & 8 days \\
\hline & & Belatacept monotherapy & 35 days \\
\hline & & Belatacept/MMF/steroids & 155 days \\
\hline & & Basiliximab induction; & $>100$ days \\
\hline & & belatacept & \\
\hline \multirow[t]{3}{*}{ Rhesus monkey ${ }^{51}$} & Islet allograft & Anti-CD40 monotherapy & 16 days \\
\hline & & Belatacept monotherapy & 59 days \\
\hline & & Belatacept/anti-CD40 & 220 days \\
\hline \multirow[t]{2}{*}{ Rhesus monkey ${ }^{52}$} & Neonatal islet & Basiliximab + anti-CDI54 & $>140$ days \\
\hline & xenograft & induction; belatacept + sirolimus & \\
\hline \multirow[t]{2}{*}{ Rhesus monkey ${ }^{53}$} & Adult islet & Basiliximab + anti-CDI54 induction; & $2 / 5(20 \%)$ \\
\hline & xenograft & belatacept + sirolimus & engraftment \\
\hline
\end{tabular}

Abbreviation: MMF, mycophenolate mofetil. 
Table 2 Clinical trials of belatacept in renal transplantation

\begin{tabular}{|c|c|c|c|c|c|}
\hline Trial & Treatment groups & $\begin{array}{l}\text { Acute } \\
\text { rejection }\end{array}$ & Graft loss & $\begin{array}{l}\text { GFR at end } \\
\text { of study ( } \mathrm{mL} / \mathrm{min})\end{array}$ & Notes \\
\hline \multirow{3}{*}{$\begin{array}{l}\text { Phase II, 6-month, } \\
\text { randomized, partially } \\
\text { blinded, parallel } \\
\text { group }^{38}\end{array}$} & MI belatacept & $5 / 74(7 \%)$ & $3 / 74(4 \%)$ & $66^{*}$ & \multirow{3}{*}{$\begin{array}{l}\text { Basiliximab induction with MMF + } \\
\text { steroids as maintenance }\end{array}$} \\
\hline & LI belatacept & $4 / 7 \mid(6 \%)$ & I/7| (I\%) & $62^{* *}$ & \\
\hline & CsA & $6 / 73(8 \%)$ & $2 / 73(3 \%)$ & 54 & \\
\hline \multirow{3}{*}{$\begin{array}{l}\text { Phase II, I-year, } \\
\text { randomized, open- } \\
\text { label }^{39}\end{array}$} & Belatacept + MMF & $5 / 33(15 \%)$ & $2 / 33(6 \%)$ & 64 & \multirow{3}{*}{$\begin{array}{l}\text { Thymoglobulin induction. } \\
P \text { values not reported }\end{array}$} \\
\hline & Belatacept + sirolimus & $\mathrm{I} / 26(4 \%)$ & $2 / 26(8 \%)$ & 62 & \\
\hline & tacrolimus + MMF & $\mathrm{I} / 30(3 \%)$ & $0 / 30(0 \%)$ & 54 & \\
\hline Phase III, & MI belatacept & $49 / 219(22 \%)$ & $4 / 219(2 \%)$ & $65^{\S}$ & \multirow{3}{*}{$\begin{array}{l}\text { One year results. Basiliximab } \\
\text { induction with } \mathrm{MMF}+\text { steroids as } \\
\text { maintenance }\end{array}$} \\
\hline randomized, partially & LI belatacept & $39 / 226(17 \%)$ & $5 / 226(2 \%)$ & $63^{\S}$ & \\
\hline $\begin{array}{l}\text { blinded, multicenter } \\
(\text { BENEFIT) })^{40}\end{array}$ & CsA & $|6 / 22|(7 \%)$ & $8 / 221(4 \%)$ & 50 & \\
\hline Phase III, & MI belatacept & $33 / 184(18 \%)$ & |7/| 84 (9\%) & $52^{\dagger}$ & One-year results. Basiliximab \\
\hline randomized, partially & LI belatacept & $31 / 175$ (I8\%) & $16 / 175$ (9\%) & $49^{\dagger \dagger}$ & induction with MMF + steroids as \\
\hline $\begin{array}{l}\text { blinded, multicenter } \\
(\text { BENEFIT-EXT) }\end{array}$ & CsA & $26 / 184(14 \%)$ & $20 / 184(11 \%)$ & 45 & maintenance \\
\hline
\end{tabular}

Abbreviations: GFR, estimated glomerular filtration rate; MI, more intensive; MMF, mycophenolate mofetil; CsA, cyclosporine A; LI, less intensive; BENEFIT, Belatacept Evaluation of Nephroprotection and Efficacy as First-line Immunosuppression Trial; BENEFIT-EXT, Belatacept Evaluation of Nephroprotection and Efficacy as First-line Immunosuppression Trial-EXTended criteria donors.

Notes: ${ }^{*} P=0.01 ;{ }^{* * P}=0.04$ versus standard $C s A ;{ }^{\circledR} P<0.01$ versus standard $C s A ;{ }^{\dagger} P<0.01 ;{ }^{\dagger t} P=0.1$ versus standard $C s A$.

upon the results published so far, patient and graft survival are similar across the three groups at both one year $(96 \%$ more intensive belatacept; $96 \%$ less intensive belatacept; and 93\% cyclosporine) and two years ( $94 \%$ more intensive belatacept; 95\% less intensive belatacept; and 91\% cyclosporine) posttransplant. ${ }^{40,41}$ At the end of one year, although the incidence of acute rejection was greater for more intensive (22\%) and less intensive (17\%) belatacept compared with cyclosporine (7\%), no apparent impact on graft survival was demonstrated. Most acute rejection episodes occurred within the first three months. Banff $\geq$ IIB acute rejection occurred more frequently in belatacept-treated (less intensive 5\%; more intensive $10 \%)$ compared with cyclosporine-treated patients (1\%). At the end of two years, glomerular filtration rate continued to be significantly higher $(15-17 \mathrm{~mL} / \mathrm{min})$ in the belatacepttreated patients. Belatacept-treated patients also had sustained benefits in their cardiovascular and metabolic risk profile.

BENEFIT-EXT (Belatacept Evaluation of Nephroprotection and Efficacy as First-line Immunosuppression TrialEXTended criteria donors) is a three-year, randomized Phase III study in renal transplant recipients receiving an extended criteria donor kidney allograft $(\mathrm{n}=543) .{ }^{42}$ The rationale for this trial was that because extended criteria donor recipients have a heightened risk of allograft loss, they might derive a significant benefit from the non-nephrotoxic belatacept. At the end of the first year, patient and graft survival was similar across the three groups. Renal function was statistically superior for more intensive belatacept versus cyclosporine $(52 \mathrm{~mL} /$ min more intensive belatacept; $45 \mathrm{~mL} / \mathrm{min}$ cyclosporine) but not for less intensive belatacept $(50 \mathrm{~mL} / \mathrm{min})$ versus cyclosporine. Surprisingly, the incidence of chronic allograft nephropathy was similar ( $45 \%$ more intensive belatacept; $46 \%$ less intensive belatacept; $52 \%$ cyclosporine) across the three groups. The recently reported two-year results echo the findings of the first year of the study, although only $64 \%$ of the originally enrolled subjects completed the study. ${ }^{43}$ In the abstract, the authors conclude that the more intensive belatacept regimen does not confer any additional efficacy over the less intensive regimen. Based upon current data, it seems likely that BENEFIT-EXT might not meet its primary endpoint of better graft survival with belatacept therapy at the end of the three-year study period. Encouragingly, though, diabetes and cardiovascular risk factors were lower in the belatacept-treated patients.

Based upon an interim report, another Phase II study is being conducted in stable renal transplant recipients maintained on calcineurin inhibitor-based regimens. Patients 6-36 months post-transplantation $(n=173)$ with glomerular filtration rates of $35-75 \mathrm{~mL} / \mathrm{min}$ were randomized to either belatacept $5 \mathrm{mg} / \mathrm{kg}$ (less intensive) or continued treatment with a calcineurin inhibitor. Seven percent of the belatacepttreated patients had acute rejection compared with none in the calcineurin inhibitor group. Although patient and graft survival remained similar in both groups, glomerular filtration rate improved significantly in the belatacept group at the end of 12 months. ${ }^{44}$

A systematic review of randomized controlled trials was recently presented at the 2010 International Congress of The 
Transplantation Society meeting. ${ }^{45}$ Based upon the report, patients treated with belatacept had a $69 \%$ lower chance of dying compared with those treated with tacrolimus. The odds ratios (ORs) of graft loss with belatacept were not statistically different relative to cyclosporine $(\mathrm{OR}=0.70,95 \%$ credible interval $0.32-1.50$ ) or tacrolimus ( $\mathrm{OR}=0.82$, credible interval $0.35-1.84$ ), although acute rejection odds were significantly higher $(\mathrm{OR}=2.61$, credible interval 1.29-4.91) relative to tacrolimus. The odds of development of newonset diabetes after transplantation were significantly lower (OR $=0.19$, credible interval 0.08-0.42) with belatacept compared with both calcineurin inhibitors.

Multiple other trials, including the use of belatacept along with various agents like sirolimus and alemtuzumab, are currently in progress. ${ }^{46}$ Because tacrolimus has largely replaced cyclosporine as the calcineurin inhibitor of choice, trials comparing tacrolimus with belatacept would be crucial in confirming the results presented above. Ashman et al reported successful use of belatacept as maintenance immunosuppression in a young kidney transplant patient who developed de novo thrombotic microangiopathy serially in association with cyclosporine, tacrolimus, and sirolimus. ${ }^{47}$ A compassionate use study to make belatacept available for renal transplant recipients who are intolerant to or having contraindications to calcineurin inhibitors and/or mTOR inhibitors is currently enrolling patients.

\section{Adverse reactions}

In human studies, belatacept appears to have predictable pharmacokinetics. No definitive relationship, however, has been established between belatacept serum concentration and the risk of acute rejection. A pooled analysis of 1425 intentto-treat patients (more intensive belatacept, $n=477$; less intensive belatacept, $\mathrm{n}=472$; cyclosporine, $\mathrm{n}=476$ ) with a median follow-up of 2.4 years demonstrated that the incidences of serious adverse events were comparable in all three groups. ${ }^{48}$ The overall incidence of malignancies was slightly higher in the more intensive belatacept group (10\% more intensive belatacept; $6 \%$ less intensive belatacept; $7 \%$ cyclosporine). A total of 15 cases of post-transplant lymphoproliferative disease, including eight cases involving the central nervous system, were reported. Of these posttransplant lymphoproliferative disease cases, eight occurred on more intensive belatacept, five on less intensive belatacept, and two on cyclosporine. Six of eight central nervous system post-transplant lymphoproliferative disease cases were reported from the more intensive belatacept group and in two of eight from the less intensive belatacept group.
EBV seronegative status was found to be the strongest risk factor. Although rates of polyomavirus infections were similar, herpes virus infections were higher in the belatacept groups. The incidence of death and serious infections was lowest in the less intensive belatacept group.

Vincenti et al recently published the five-year safety data of their initial Phase II study. ${ }^{49}$ Belatacept-treated patients did not have a higher frequency of serious infections or post-transplant lymphoproliferative disease compared with cyclosporine. Serious cardiac disorders occurred more frequently with cyclosporine ( $2 \%$ for belatacept versus $12 \%$ for cyclosporine). Haidinger et al reported a renal transplant recipient on belatacept who developed fatal Pneumocystis jiroveci pneumonia four years post-transplant. ${ }^{50}$ Cytomegalovirus infection preceded the pneumonia, illustrating that excessive immunosuppression can result, even with a lymphocyte-specific regimen.

\section{Conclusion}

Belatacept, a selective $\mathrm{T}$ cell costimulation blocker, is a promising new therapy for maintenance immunosuppression among renal transplant recipients. It was originally anticipated that costimulation blockade would be successful in achieving immunologic allograft tolerance, but based upon current data this does not appear to be the case. Thus, the new paradigm revolves around the use of belatacept (among other molecules) for avoidance of calcineurin inhibitor nephrotoxicity and minimization of long-term cardiovascular and metabolic side effects. One main limitation of this medication is that administration requires an intravenous infusion. Although scheduled monthly infusions might improve compliance among a certain patient subset, eg, children, most mobile patients and those in remote locations could find themselves unable to adhere to such therapy. Furthermore, because the drug has a long half-life of 8-10 days, it might be difficult to dose patients battling with life-threatening infections appropriately. Owing to concerns about an increased post-transplant lymphoproliferative disease risk in EBV seronegative patients, current belatacept trial protocols have now been modified to enroll EBV seropositive patients only. Unfortunately, this exclusion will complicate the introduction of this drug for young patients, who might derive the maximum long-term benefit from non-nephrotoxic regimens. On a positive note, animal and human studies have demonstrated that the use of belatacept can lead to better renal function, along with a lower incidence of diabetes and cardiovascular risk factors. Although acute rejection seems to be more frequent with belatacept, so far there are no data to suggest that 
long-term renal allograft survival is shortened. Of course, the observed benefits in renal function as measured by calculated glomerular filtration rate will need to be confirmed using hard endpoints, including patient and allograft survival.

\section{Disclosure}

Karl L Womer is a recipient of salary support from BristolMyers Squibb.

\section{References}

1. Suthanthiran M, Strom TB. Renal transplantation. N Engl J Med. 1994; 331(6):365-376.

2. Organ Procurement and Transplant Network/Scientific Registry of Transplant Recipients Annual Report. 2009 Donation and transplantation trends. Available at: http://optn.transplant.hrsa.gov/latestData. Accessed 2010 Nov 10.

3. Cecka JM. The OPTN/UNOS Renal Transplant Registry. Clin Transpl. 2005:1-16

4. Samaniego M, Becker BN, Djamali A. Drug insight: Maintenance immunosuppression in kidney transplant recipients. Nat Clin Pract Nephrol. 2006;2(12):688-699.

5. Tantravahi J, Womer KL, Kaplan B. Why hasn't eliminating acute rejection improved graft survival? Annu Rev Med. 2007;58:369-385.

6. Organ Procurement and Transplantation Network, based on OPTN data as of September 24, 2010. Available at: http://optn.transplant.hrsa.gov/ latestData. Accessed 2010 Nov 10.

7. Pascual M, Theruvath T, Kawai T, Tolkoff-Rubin N, Cosimi AB. Strategies to improve long-term outcomes after renal transplantation. N Engl J Med. 2002;346(8):580-590.

8. Nankivell BJ, Borrows RJ, Fung CL, O'Connell PJ, Allen RD, Chapman JR. The natural history of chronic allograft nephropathy. N Engl J Med. 2003;349(24):2326-2333.

9. Arend SM, Mallat MJ, Westendorp RJ, van der Woude FJ, van Es LA. Patient survival after renal transplantation; more than 25 years follow-up. Nephrol Dial Transplant. 1997;12(8):1672-1679.

10. Ojo AO. Cardiovascular complications after renal transplantation and their prevention. Transplantation. 2006;82(5):603-611.

11. Womer K, Rabb H. Immunosuppressive medications in kidney transplantation. In: Feehally J, Johnson R, Floege J, editors. Comprehensive Clinical Nephrology. 4th ed. Mosby; 2010.

12. Glotz D, Charpentier B, Abramovicz D, et al. Thymoglobulin induction and sirolimus versus tacrolimus in kidney transplant recipients receiving mycophenolate mofetil and steroids. Transplantation. 2010;89(12):1511-1517.

13. Jacquet A, Francois H, Frangie C, Ahmad L, Charpentier B, Durrbach A. Prevention of calcineurin inhibitor nephrotoxicity in renal transplantation. Transpl Immunol. 2008;20(1-2):29-31.

14. Buchler M, Caillard S, Barbier S, et al. Sirolimus versus cyclosporine in kidney recipients receiving thymoglobulin, mycophenolate mofetil and a 6-month course of steroids. Am J Transplant. 2007;7(11):2522-2531.

15. 2008 Annual Report of the US Organ Procurement and Transplantation Network and the Scientific Registry of Transplant Recipients: Transplant Data 1998-2007. Available at: http://www.ustransplant. org/annual_reports/current/506d_ki.htm. Accessed 2010 Nov 10.

16. Cooper JE, Wiseman AC. Novel immunosuppressive agents in kidney transplantation. Clin Nephrol. 2010;73(5):333-343.

17. Huang E, Womer K, Vincenti F. Biological agents in kidney transplantation. In: Pereira B, Sayegh M, Blake P, editors. Chronic Kidney Disease, Dialysis, and Transplantation. 3rd ed. Philadelphia, PA: Elsevier Saunders; 2010.

18. Womer $\mathrm{K}, \mathrm{Rabb} \mathrm{H}$. Immunologic principles in kidney transplantation. In: Feehally J, Johnson R, Floege J, editors. Comprehensive Clinical Nephrology. 4th ed. Mosby; 2010.
19. Fife BT, Bluestone JA. Control of peripheral T-cell tolerance and autoimmunity via the CTLA-4 and PD-1 pathways. Immunol Rev. 2008;224:166-182.

20. Li XC, Rothstein DM, Sayegh MH. Costimulatory pathways in transplantation: Challenges and new developments. Immunol Rev. 2009; 229(1):271-293.

21. Linsley PS, Wallace PM, Johnson J, et al. Immunosuppression in vivo by a soluble form of the CTLA-4 T cell activation molecule. Science. 1992;257(5071):792-795.

22. Kremer JM, Westhovens R, Leon M, et al. Treatment of rheumatoid arthritis by selective inhibition of T-cell activation with fusion protein CTLA4Ig. N Engl J Med. 2003;349(20):1907-1915.

23. Abrams JR, Kelley SL, Hayes E, et al. Blockade of T lymphocyte costimulation with cytotoxic $\mathrm{T}$ lymphocyte-associated antigen 4-immunoglobulin (CTLA4Ig) reverses the cellular pathology of psoriatic plaques, including the activation of keratinocytes, dendritic cells, and endothelial cells. J Exp Med. 2000;192(5):681-694.

24. Levisetti MG, Padrid PA, Szot GL, et al. Immunosuppressive effects of human CTLA4Ig in a non-human primate model of allogeneic pancreatic islet transplantation. J Immunol. 1997;159(11):5187-5191.

25. Linsley PS, Greene JL, Brady W, Bajorath J, Ledbetter JA, Peach R. Human B7-1 (CD80) and B7-2 (CD86) bind with similar avidities but distinct kinetics to CD28 and CTLA-4 receptors. Immunity. 1994;1(9):793-801.

26. Larsen CP, Pearson TC, Adams AB, et al. Rational development of LEA29Y (belatacept), a high-affinity variant of CTLA4-Ig with potent immunosuppressive properties. Am J Transplant. 2005;5(3):443-453.

27. Latek R, Fleener C, Lamian V, et al. Assessment of belatacept-mediated costimulation blockade through evaluation of CD80/86-receptor saturation. Transplantation. 2009;87(6):926-933.

28. Davis PM, Nadler S, Suchard SJ. Belatacept does not mediate complement-dependent cytotoxicity or antibody-dependent cellular cytotoxicity. Am J Transplant. 2008;8:619.

29. Sakaguchi S, Sakaguchi N, Shimizu J, et al. Immunologic tolerance maintained by $\mathrm{CD} 25+\mathrm{CD} 4+$ regulatory $\mathrm{T}$ cells: Their common role in controlling autoimmunity, tumor immunity, and transplantation tolerance. Immunol Rev. 2001;182:18-32.

30. Tang Q, Henriksen KJ, Boden EK, et al. Cutting edge: CD28 controls peripheral homeostasis of CD4+CD25+ regulatory T cells. J Immunol. 2003;171(7):3348-3352.

31. Rangel EB. Belatacept in clinical and experimental transplantation progress and promise. Drugs Today (Barc). 2010;46(4):235-242.

32. Bluestone JA, Liu W, Yabu JM, et al. The effect of costimulatory and interleukin 2 receptor blockade on regulatory $T$ cells in renal transplantation. Am J Transplant. 2008;8(10):2086-2096.

33. Vierboom MP, Ossevoort M, Sick EA, Haanstra K, Jonker M. Induction of allograft tolerance through costimulatory blockade: First selection of drugs in vitro. Transpl Immunol. 2003;11(2):215-222.

34. Kirk AD, Tadaki DK, Celniker A, et al. Induction therapy with monoclonal antibodies specific for CD80 and CD86 delays the onset of acute renal allograft rejection in non-human primates. Transplantation. 2001;72(3):377-384.

35. Montgomery SP, Xu H, Tadaki DK, et al. Combination induction therapy with monoclonal antibodies specific for CD80, CD86, and CD154 in nonhuman primate renal transplantation. Transplantation. 2002;74(10):1365-1369.

36. Emamaullee JA, Merani S, Larsen CP, Shapiro AM. Belatacept and basiliximab diminish human antiporcine xenoreactivity and synergize to inhibit alloimmunity. Transplantation. 2008;85(1):118-124.

37. Li C, Yang CW. The pathogenesis and treatment of chronic allograft nephropathy. Nat Rev Nephrol. 2009;5(9):513-519.

38. Vincenti F, Larsen C, Durrbach A, et al. Costimulation blockade with belatacept in renal transplantation. $N$ Engl J Med. 2005;353(8): 770-781.

39. Ferguson R, Vincenti F, Kaufman D, et al. Immunosuppression with belatacept-based, CNI-avoiding and steroid-avoiding regimens vs a tacrolimus-based, steroid-avoid regimen in kidney transplant patients: Results of a 1-year, randomized study. Transplantation. 2010;90 Suppl:156. 
40. Vincenti F, Charpentier B, Vanrenterghem Y, et al. A phase III study of belatacept-based immunosuppression regimens versus cyclosporine in renal transplant recipients (BENEFIT study). Am J Transplant. 2008; 10(3):535-546.

41. Larsen C, Grinyo JM, Charpentier B, et al. Belatacept vs cyclosporine in kidney transplant recipients: Two-year outcomes from the BENEFIT study. Transplantation. 2010;90 Suppl:158.

42. Durrbach A, Pestana JM, Pearson T, et al. A phase III study of belatacept versus cyclosporine in kidney transplants from extended criteria donors (BENEFIT-EXT study). Am J Transplant. 2010;10(3):547-557.

43. Durrbach A, Larsen C, Pestana JOM, et al. Belatacept vs cyclosporine in ECD kidney transplants: Two-year outcomes from the BENEFIT-EXT study. Transplantation. 2010;90 Suppl:157.

44. Rostaing L, Nainan G, Rial MC, et al. Switch from a CNI- to a belatacept-based immunosuppressive regimen in kidney transplant recipients is safe and results in better renal function: 12 month results from a Phase II study. Transplantation. 2010;90 Suppl:157.

45. Goring S, Eyawo O, Mills EJ, et al. A mixed treatment comparison of efficacy and cardiometabolic safety of belatacept, cyclospoorine and tacrolimus for immunosuppression therapy in adult renal transplant receipients. Transplantation. 2010;90 Suppl:75.

46. Vincenti F, Kirk AD. What's next in the pipeline. Am J Transplant. 2008;8(10):1972-1981.
47. Ashman N, Chapagain A, Dobbie H, et al. Belatacept as maintenance immunosuppression for postrenal transplant de novo drug-induced thrombotic microangiopathy. Am J Transplant. 2009;9(2): 424-427.

48. Grinyo J, Charpentier B, Pestana J, et al. Safety profile of belatacept in kidney transplant recipients from a pooled analysis of phase II and phase III studies. Transplantation 2010;90 Suppl:156.

49. Vincenti F, Blancho G, Durrbach A, et al. Five-year safety and efficacy of belatacept in renal transplantation. J Am Soc Nephrol. 2010;21(9): 1587-1596.

50. Haidinger M, Hecking M, Memarsadeghi M, et al. Late onset Pneumocystis pneumonia in renal transplantation after long-term immunosuppression with belatacept. Transpl Infect Dis. 2009;11(2): $171-174$.

51. Adams AB, Shirasugi N, Jones TR, et al. Development of a chimeric anti-CD40 monoclonal antibody that synergizes with LEA29Y to prolong islet allograft survival. J Immunol. 2005;174(1):542-550.

52. Cardona K, Korbutt GS, Milas Z, et al. Long-term survival of neonatal porcine islets in nonhuman primates by targeting costimulation pathways. Nat Med. 2006;12(3):304-306.

53. Cardona K, Milas Z, Strobert E, et al. Engraftment of adult porcine islet xenografts in diabetic nonhuman primates through targeting of costimulation pathways. Am J Transplant. 2007;7(10):2260-2268.
Drug Design, Development and Therapy

\section{Publish your work in this journal}

Drug Design, Development and Therapy is an international, peerreviewed open-access journal that spans the spectrum of drug design and development through to clinical applications. Clinical outcomes, patient safety, and programs for the development and effective, safe, and sustained use of medicines are a feature of the journal, which

\section{Dovepress}

has also been accepted for indexing on PubMed Central. The manuscript management system is completely online and includes a very quick and fair peer-review system, which is all easy to use. Visit http://www.dovepress.com/testimonials.php to read real quotes from published authors.

Submit your manuscript here: http://www.dovepress.com/drug-design-development-and-therapy-journal 